\title{
FIXAÇÃO DE REGIME MAIS BRANDO PARA CUMPRIMENTO INICIAL DA PENA PRIVATIVA DE LIBERDADE
}

\section{MILD REGIME FIXING FOR AN INITIAL ACCOMPLISHMENT OF RESTRICTIVE PENALTY OF FREEDOM}

\section{Laura Costa ${ }^{1}$ \\ Poliana Costa ${ }^{2}$}

Resumo: O presente estudo apre- dades de reprovação e prevenção senta uma breve análise sobre a da pena, a teoria adotada pelo orpossibilidade de fixação do regi- denamento brasileiro, bem como me inicial aberto de cumprimen- os critérios para a fixação do reto da pena privativa de liberdade gime inicial de cumprimento da nas hipóteses em que o regime pena. Superado o embasamento legal não se mostre necessário teórico, são apresentadas consiao atendimento dos fins de repro- derações sobre o panorama geral vação e prevenção da pena. São do atual sistema carcerário, da abordadas, inicialmente, as finali- violação à dignidade do recluso

1 Graduada em Direito pelo Complexo de Ensino Superior de Santa Catarina (Cesusc). Atualmente é advogada, inscrita na OAB/SC n. 50.966. E-mail: lauracosta815@gmail.com

2 Graduada em Direito pela Universidade Federal de Santa Catarina (UFSC) e especialista em Direito Público e em Prática Jurídica pela Universidade Regional de Blumenau (Furb). Atualmente desempenha a função de Técnica Judiciária Auxiliar na DiretoriaGeral Judiciária no Tribunal de Justiça de Santa Catarina. E-mail: polianacosta@tjsc.jus.br 
e da incapacidade de atendimento da finalidade ressocializadora da pena. São analisados os critérios autorizadores da fixação do regime mais gravoso do que o legal, a fim de aferir se a mesma lógica autoriza a fixação do regime mais brando. Ao final, são feitas ponderações sobre a suficiência e a necessidade da pena, bem como são feitas proposições de critérios a serem utilizados na fixação do regime menos gravoso.

Palavras-chave: Finalidades da pena. Pena privativa de liberdade. Sistema penitenciário. Dessocialização. Suficiência e necessidade da pena. Regime mais brando de cumprimento da pena (regime aberto).

Abstract: The present study presents a brief analysis on the possibility of fixing the initial open regime fulfilling the restrictive penalty of freedom, on the hypothesis where a legal regime does not appear to be necessary to attend disapproval and crime prevention. Firstly, the disapproval and crime prevention purposes are presented, along with the theory adopted by the Brazilian ordering, and the initial open regime fixing criteria for penalties accomplishment. With the theoretical basis settled, the next considerations are about the general view of the contemporary prison system, the defendant's dignity violation, and the incapacity to attempt the penalty resocialization purposes. The fixing authorizers' criteria for a severer regime than the legal one are analyzed, aiming to understand if the same logic authorizes a mild regime. In the end, deliberations about the necessity and sufficiency of the penalty are made, as well as the propositions for a criterion for fixing the mild regime.

Keywords: Penalties purposes. Restrictive penalty of freedom. Prison system. Desocialization. Necessity and sufficiency of the penalty. Mild regime of sentence accomplishment (open regime).

\section{INTRODUÇÃO}

A vida em sociedade sempre esteve associada à prática de crimes. A despeito disso, inegável que a sociedade atingiu níveis históricos de criminalidade e de violência urbana, o que desencadeia acirrados debates sobre o atual sistema punitivo e a atuação do Poder Judiciário. 
Nesse contexto, parece que a resposta se encontra no encarceramento do criminoso como única alternativa à impunidade.

Tal postura, entretanto, desconsidera a incapacidade de o sistema penitenciário atender à finalidade preventiva da pena, bem como que a precariedade de suas condições afronta a dignidade humana do recluso.

Dentro desse quadro, o objetivo geral perseguido, formulado como hipótese de investigação, é demonstrar que o juiz poderá abandonar a atuação meramente subsuntiva e padronizada da norma a fim de atenuar o rigor repressivo diante das circunstâncias do caso concreto, ponderando as implicações decorrentes das falhas do sistema punitivo penal.

Como um dos tantos outros instrumentos que podem ser utilizados para efeito de atenuação do rigor repressivo, propõe-se que seja fixado regime mais brando do que o quantitativamente previsto em lei, ampliando-se a utilização do regime inicial aberto.

Objetiva-se, com o trabalho, verificar a validade desse procedimento, bem como seus limites e sua excepcionalidade.

No presente trabalho, a metodologia utilizada será a revisão bibliográfica, sendo que o método de abordagem será o hipotético-dedutivo, uma vez que a hipótese principal tentará ser confirmada.

Passa-se a expor como será feita a abordagem do tema.

Serão elencados, inicialmente, as finalidades de reprovação e prevenção da pena, a teoria adotada pelo ordenamento brasileiro, bem como os critérios para fixação do regime inicial de cumprimento da pena.

Superado o embasamento teórico, serão apresentadas considerações sobre o panorama geral do atual sistema carcerário, da violação à dignidade do recluso e da incapacidade de aten- 
dimento da finalidade ressocializadora da pena. Ainda serão analisados os critérios autorizadores da fixação do regime mais gravoso do que o legal a fim de aferir se a mesma lógica autoriza a fixação do regime mais brando.

Ao final, serão feitas ponderações sobre a suficiência e a necessidade da pena, bem como serão feitas proposições de critérios a serem utilizados na fixação do regime menos gravoso.

Nessa linha de raciocínio, será proposta a ampliação da utilização do $\S 3^{\circ}$ do art. 33 do Código Penal como forma de viabilizar a fixação do regime mais brando do que o legal nas hipóteses em que a prisão não se mostre necessária para atender aos fins de retribuição e prevenção da pena.

Para tanto, será examinado o entendimento das cortes superiores que autoriza a fixação de regime mais gravoso a fim de aferir se a mesma lógica autorizaria a fixação do regime menos gravoso. Por fim, será proposto, de forma concreta, critérios e limites que poderiam ser adotados na utilização desse mecanismo.

\section{A PENA}

Serão elencados, neste tópico, as finalidades de reprovação e prevenção da pena, a teoria adotada pelo ordenamento brasileiro, assim como os critérios para fixação do regime inicial de cumprimento da pena.

\subsection{Suas finalidades}

Ao longo da evolução do direito penal, muito se debateu sobre quais as finalidades que o Estado pode e deve perseguir por meio da pena. E tal discussão tem razão de ser. Todas as questões relativas ao porquê e ao para que punir estão ligadas, definitivamente, ao problema da legitimação ou fundamentação dos limites do poder estatal de privar a liberdade ou restringir os direitos de algum dos seus cida- 
dãos. E não há dúvidas que tais questões são de alta relevância e inegável atualidade.

Portanto, várias teorias surgiram na tentativa de explicar a finalidade da pena, cujas linhas mestras serão sinteticamente mencionadas a seguir.

Primeiramente, cumpre ressaltar as teorias tidas como absolutas, as quais advogam a tese de que a pena é uma reprovação que se faz ao autor de um delito, tendo um caráter meramente retributivo. Logo, a reprimenda corresponde a um castigo, consistente em pagar um mal (a prática do crime) com outro mal (a pena).

Nessa teoria, não há uma preocupação com o futuro (prevenção), apenas uma retribuição moral pelo passado. Sob essa ótica, a pena não teria finalidade útil alguma, possuindo fim em si mesma e devendo existir apenas para que a justiça impere. Nesse sentido, leciona Roxin (1997, p. 81-82):

[...] a teoria da retribuição não encontra o sentido da pena na perspectiva de algum fim socialmente útil, senão em que mediante a imposição de um mal merecidamente se retribui, equilibra e espia a culpabilidade do autor pelo fato cometido, se fala aqui de uma teoria 'absoluta' porque para ela o fim da pena é independente, 'desvinculado’ de seu efeito social. A concepção da pena como retribuição compensatória realmente já é conhecida desde a antiguidade e permanece viva na consciência dos profanos com uma certa naturalidade: a pena deve ser justa e isso pressupõe que se corresponda em sua duração e intensidade com a gravidade do delito, que o compense.

Apesar de a referida teoria se afastar do fim social, a maior virtude do retribucionismo é ter trazido ao direito penal a ideia de proporcionalidade. Outro grande mérito do caráter retributivo foi ter erigido a culpabilidade como fundamento para a 
aplicação da pena, pois essa, independentemente dos fins a que se destina, deve ter sempre um delito como pressuposto.

Tais méritos, porém, não são suficientes para validar a teoria retributiva.

Isso porque a proporcionalidade e a culpabilidade podem e devem servir como limite ao poder punitivo do Estado, entretanto não como fundamento desse mesmo poder.

Logo, a despeito do ideário social e da força do caráter retributivo, não soa racional ou apropriado à dignidade da pessoa humana (como fundamento do Estado Democrático de Direito) que a pena seja tão somente um mal, desprovida de qualquer utilidade, o que já é suficiente para afastar a finalidade retributiva, em sua acepção pura, do ordenamento jurídico brasileiro, por afronta ao art. $1^{\circ}$, inciso III, da Constituição Federal.

Em contrapartida à teoria supramencionada, a prevenção mira o futuro, no sentido de prevenir a ocorrência de futuros delitos, numa visão útil para a sociedade, pois, além de servir de exemplo (prevenção geral), age de forma direta sobre a individualidade do infrator, almejando seu retorno harmônico ao convívio social (prevenção especial).

Nesse diapasão, citem-se os esclarecimentos de Cleber Masson (2009, p. 526):

Para essa variante, a finalidade da pena consiste em prevenir, isto é, evitar a prática de novas infrações penais (punitur ne peccetur). É irrelevante a imposição de castigo ao apenado. Adota-se uma posição absolutamente contrária à teoria absoluta. Destarte, a pena não está destinada à realização da justiça sobre a terra, servindo apenas para a proteção da sociedade. A pena não se esgota em sim mesma, despontando como meio cuja finalidade é evitar futuras ações puníveis. 
Assim, as teorias relativas são todas as doutrinas utilitaristas, que justificam a pena como meio para a realização do fim utilitário de prevenção de outros delitos. E, diferentemente da intenção de "fazer justiça", que é absoluta, as necessidades de prevenção são relativas e circunstanciais.

Disso decorre que a pena não deve servir à realização da justiça absoluta, mas à proteção da sociedade. Os fundamentos ideológicos das teorias relativas da pena vêm do iluminismo, que, mediante uma racionalidade orientada a evitar o cometimento de delitos, procurou dar uma perspectiva também humanitária e social à persecução dessa finalidade (MALGARIN, 2015, p. 14).

Cumpre ressaltar que a teoria relativa, seguindo a classificação tradicional utilizada pelos penalistas ao analisar as diversas finalidades da pena, a subdivide em prevenção geral (destinada a toda a sociedade) e prevenção especial (destinada ao indivíduo que praticou o crime). Essas, por sua vez, também se subdividem, sendo que ambas apresentam vertentes negativa e positiva.

Pois bem, a prevenção geral é destinada ao controle da violência, a qual, utilizando-se da expressão de Santos (2008, p. 466), tem por objetivo evitar o crime futuro mediante uma forma negativa antiga e uma forma positiva pós-moderna.

Nesse viés, vale ressaltar as palavras do grande marco da história penal - Cesar Bonesana Marquês de Beccaria, autor da obra "Dos delitos e das Penas":

[...] Poderão os gritos de um desgraçado nas torturas tirar do seio do passado, que não volta mais, uma ação já praticada? Não. Os castigos têm por finalidade única obstar o culpado de tornar-se futuramente prejudicial à sociedade e afastar os seus concidadãos do caminho do crime. (BECCARIA, 2006, p. 49).

A prevenção geral negativa, também conhecida como intimidatória ou dissuasória, traz a ideia de intimidação psicoló- 
gica da pena, tendo como grande expoente Feuerbach. Nessa concepção, a finalidade da pena é impedir as lesões jurídicas por meio de uma coação psicológica, instrumentalizada pelo Estado, qual seja, "se você violar a lei criminal, sofrerá uma pena". Tem, portanto, o propósito de criar, no espírito dos potenciais criminosos, um contraestímulo suficientemente forte para afastá-los da prática do crime.

Enquanto a vertente positiva da prevenção geral (reforçadora) comumente é definida como integração/prevenção, o objetivo perseguido com a pena é a conservação da confiança na firmeza e no poder de execução do ordenamento jurídico (MALGARIN, 2015, p. 20).

Nesse sentido, Roxin (1997, p. 468) define a chamada integração/prevenção como:

[...] demonstração da inviolabilidade do Direito, necessária para preservar a confiança na ordem jurídica e reforçar a fidelidade jurídica do povo, destacando uma tríplice superposição de efeitos político-criminais: primeiro, o efeito sócio-pedagógico de exercício em fidelidade jurídica, produzido pela atividade da justiça penal; segundo, o efeito de aumento da confiança do cidadão no ordenamento jurídico pela percepção da imposição do Direito; terceiro, o efeito de pacificação social pela punição da violação do Direito e, portanto, solução do conflito com o autor.

Portanto, cada vez que se comete um delito, a consciência jurídica da comunidade, que presumidamente aceita a validade do ordenamento jurídico, também se vê atacada com maior ou menor intensidade. Com a pena, conseguir-se-ia um fim de integração do delinquente e da comunidade com a norma, restabelecendo-se esta. Daí a denominação "prevenção de integração" para a prevenção geral positiva. 
Por sua vez, a prevenção especial possui pretensão diametralmente oposta à prevenção geral, uma vez que a finalidade da pena, para os adeptos dessa teoria, é dissuadir o ser humano, individualmente considerado, da prática de outros delitos.

Trata-se, na verdade, de evitar que aqueles que praticaram um delito voltem a fazê-lo no futuro. Assim, a ideia central é impedir ou dificultar a reincidência por meio da atuação sobre o infrator.

A prevenção especial se subdivide em duas classificações, quais sejam, negativa e positiva. Cumpre salientar que a prevenção especial negativa não possui o intento de melhorar o detento, mas, tão somente, "neutralizar os efeitos de sua inferioridade, à custa de um mal para a pessoa, que ao mesmo tempo é um bem para o corpo." (ZAFFARONI, 2013, p. 127).

Nessa acepção, o que importa, portanto, é a sociedade. Neutralizar o criminoso baseado na premissa de que sua privação de liberdade produz segurança social. Assim, evidente que, durante o cumprimento da pena privativa de liberdade, o indivíduo fica, teoricamente, impedido de cometer crimes fora dos limites da prisão.

Assim, não há dúvidas de que a neutralização que decorre da segregação é uma das funções manifestas ou declaradas que é cumprida com a pena criminal.

Por fim, para a prevenção especial positiva, segundo Roxin (1997 apud GRECO, 2015, p. 538), "a missão da pena consiste unicamente em fazer com o que o autor desista de cometer futuros delitos".

Partindo da premissa de que o condenado à pena privativa de liberdade irá retornar à sociedade, a pena busca sua reinserção ao corpo social, incentivando a atividades produtivas e educativas. Existe, ao que parece, um claro objetivo de trata- 
mento do delinquente para que adquira valores, incorpore-os ao seu espírito e aplique-os ao seu cotidiano em sociedade.

\subsection{Do critério adotado pelo artigo 59 do CP}

Os doutrinadores nacionais mantiveram-se filiados às teorias ecléticas ou mistas da pena, que unificam as ideias de retribuição e prevenção, tanto geral (ameaça a todos) como especial (evitar reincidência do criminoso) (MALGARIN, 2015, p. 25).

$\mathrm{O}$ art. 59 do Código assumiu expressamente um duplo sentido para a pena: retribuição e prevenção. Diz textualmente: "O juiz, atendendo à culpabilidade [...], estabelecerá, conforme seja necessário e suficiente para a reprovação e prevenção do crime: as penas aplicáveis dentre as cominadas [...]" (BRASIL, 1940).

Destas expressões, reprovação e prevenção, do crime é possível extrair a tríplice função atribuída à pena criminal: retribuição (relacionada à reprovação); prevenção geral (intimidação e manutenção/reforço da confiança na ordem jurídica); e prevenção especial (ressocialização e neutralização do autor).

Contudo, não existe prevalência da retribuição nem da prevenção, porque tais fatores coexistem, somando-se, sem que exista uma hierarquia. Nessa linha, segue o entendimento do Supremo Tribunal de Justiça:

[...] Deveras, a pena assume o caráter de prevenção e retribuição ao mal causado. Por outro lado, não se pode olvidar seu necessário caráter ressocializador, devendo preocupar-se o Estado, portanto, em recuperar o apenado [...] (BRASIL, 2014).

\subsection{Dos regimes de cumprimento}

O sistema penal brasileiro é estruturado pelo critério dualista alternativo, que se caracteriza pela aplicação da pena criminal - fundada na culpabilidade - ou da medida de segurança - fundada na periculosidade. 
Especificamente no que se refere à pena criminal, verifica-se que esta é de três espécies: privativas de liberdade, restritiva de direitos e multa (art. 32, I, II e III, do CP):

No sistema penal, as penas privativas de liberdade constituem o centro da política penal e a forma principal de punição; as penas restritivas de direitos funcionam, simultaneamente, como substitutivas da privação de liberdade e impeditivas da ação criminogênica do cárcere; as penas de multa são, em regra, cominadas em forma cumulativa ou alternativa à privação de liberdade; por exceção, podem ser aplicadas em caráter substitutivo das penas privativas de liberdade (art. $\left.60, \S 2^{\circ}, \mathrm{CP}\right)$. (SANTOS, 2007, p. 282).

Sem pretensão de aprofundamento no que se refere às espécies de pena para que não se perca o foco no objeto do presente estudo, mas se restringindo ao exame da pena privativa de liberdade, o Código Penal estabelece que esta pode ser de reclusão e detenção.

Os critérios para fixação do regime inicial de cumprimento da pena privativa de liberdade encontram-se no art. 33 do mesmo diploma legal, que estabelece três diferentes regimes: fechado, semiaberto ou aberto.

A escolha do regime inicial de cumprimento da pena deve observar quatro fatores elencados pela doutrina e jurisprudência:

a) Tipo da pena: reclusão ou detenção;

b) Quantidade da pena definitiva, conforme critérios estabelecidos no $\S 2^{\circ}$, do art. 33, do Código Penal;

c) Reincidência; e

d) Circunstâncias judiciais do artigo 59, do Código Penal. (MALGARIN, 2015, p. 27).

Dessa feita, fixado o quantum da pena, conforme o critério trifásico estabelecido no art. 68, do Código Penal, o magistrado determinará o regime inicial com certa discricionariedade, 
já que tal atividade não leva em conta apenas aspectos objetivos (tipo e quantidade de pena), mas também dados subjetivos (reincidência e circunstâncias judiciais).

Apesar de tais critérios aparentem ser satisfatórios na maioria das hipóteses, viabilizando adequada e proporcional fixação do regime de cumprimento, observa-se que algumas situações concretas, diante de suas peculiaridades, reclamam interpretação ampliada e associada ao atendimento da função da pena, o que será objeto de abordagem em tópico posterior.

\subsection{A finalidade da pena nos diferentes momentos da individualização}

A diversidade de funções atribuídas à pena criminal evidencia-se nos três níveis de sua individualização.

De regra, diz-se que a atividade legiferante consistente na cominação da ameaça penal constante no tipo legal cumpre a função de prevenção geral negativa.

As funções de retribuição e de prevenção geral positiva encontram-se presentes na aplicação judicial da pena, a teor do art. 59 do Código Penal. Por fim, é na execução penal que se espera serem atendidas as funções de prevenção especial positiva (correção) e negativa (neutralização) da pena (MALGARIN, 2015, p. 21).

Roxin (1997, p. 77, grifo nosso) atribui à pena finalidades distintas, segundo cada uma dessas fases:

(a) no momento da cominação legal abstrata a pena tem finalidade preventiva geral negativa e positiva, já que visa tanto intimidar quanto chamar a atenção para a relevância do bem jurídico protegido;

(b) na fase da aplicação judicial a pena tem finalidade preventiva geral (confirmação da seriedade da ameaça abstrata, assim como da importância do bem jurídico 
violado), repressiva (reprovação do mal do crime, fundada e limitada pela culpabilidade) e preventiva especial (atenuação do rigor repressivo para privilegiar institutos ressocializadores alternativos: penas substitutivas, sursis etc.);

(c) na fase da execução penal, a teor do que estabelece o artigo $1^{\circ}$ da Lei de Execução Penal, prepondera a finalidade de prevenção especial positiva. Entretanto, na prática, o que se cumpre é a função preventiva negativa da inocuização (mero enclausuramento, sem nenhum tipo de assistência ao recluso, nem oferta das condições propícias à sua reinserção social).

\section{POSSIBILIDADE DE FIXAÇÃO DE REGIME DE CUMPRIMENTO DE PENA MAIS BRANDO}

Superado o embasamento teórico, serão apresentadas considerações sobre o panorama geral do atual sistema carcerário, da violação à dignidade do recluso e da incapacidade de atendimento da finalidade ressocializadora da pena. Ainda serão analisados os critérios autorizadores da fixação do regime mais gravoso do que o legal a fim de aferir se a mesma lógica autoriza a fixação do regime mais brando, segundo os julgados dos Tribunais Superiores e da Corte Catarinense.

\subsection{A dessocialização da reclusão no atual sistema carcerário}

Cesar Roberto Bitencourt (2012, p. 162) salienta que, a partir do século XIX, quando a prisão converteu-se na principal resposta penológica, havia um ambiente muito otimista acerca de sua eficácia como meio de obtenção da reforma do delinquente. Tinha-se a firme convicção da idoneidade da prisão como forma de realização de todas as finalidades da pena. 
Contudo, não há dúvidas de que esse mesmo otimismo se esvaneceu há muito tempo. A pena privativa de liberdade está em crise e, especialmente, seu objetivo ressocializador.

Como bem salienta Luiz Flavio Gomes (2006, p. 1), a pena de prisão, no Brasil, é cumprida de maneira totalmente inconstitucional, uma vez que é desumana, cruel e torturante. Os presídios não apresentam condições mínimas para ressocializar alguém. Ao contrário, dessocializam, produzindo efeitos devastadores na personalidade da pessoa.

Nesse ponto, há quem diga que a pena privativa de liberdade não deixou de ser uma pena corporal. $\mathrm{O}$ médico psiquiatra francês Daniel Gonin (apud VIEIRA, 2007) publicou, na França, o livro La Sante Incarcéré e Médecine et Conditions de Vieen Détention (a saúde médica do cárcere e as condições de vida em detenção), em que relata a respeito do encarceramento no corpo do detento, constatando que a pena privativa de liberdade impõe grande sofrimento ao corpo do encarcerado.

$\mathrm{Na}$ obra supracitada, retira-se a informação que 31\% (trinta e um por cento) dos apenados afirmam ter sentido uma diminuição de suas capacidades visuais. Gonin (apud VIEIRA, 2007) aponta a causa: condições precárias de iluminação, obrigatoriedade de estar cabisbaixo, entre outras. Em resumo: o cárcere atinge o corpo do detento deixando marcas para o resto de sua vida.

Inquestionavelmente, a prisionalização é um processo que leva a uma meta diametralmente oposta à ressocialização, já que "não o prepara para o retorno à vida em sociedade, ao contrário, interioriza valores e regras diversos desta subcultura", sendo, portanto, fator que dificulta ou mesmo inviabiliza a ressocialização (MALGARIN, 2015, p. 44).

Porém, seria leviano afirmar que a prisionalização conduza à inevitável criminalidade pós-soltura. Cada indivíduo reage 
de forma diferente, e não há estudos conclusivos acerca da extensão de seus efeitos e sua relação com a reincidência.

Ademais, ainda que se obtivesse êxito na ressocialização, constata-se que alguns reclusos já são aparentemente "socializados", uma vez que possuem estudo, profissão, ou seja, estão em uma sociedade na qual parecem estar plenamente habilitados a conviver. Em tais casos, ao que parece, a prisão nunca teria um efeito ressocializador (nos moldes em que a ressocialização é concebida), mas apenas segregador.

Destacando a inaptidão do sistema carcerário em atender ao declarado propósito ressocializador, bem como as nefastas consequências pós-reclusão, aduz Evandro Lins e Silva (2017, p. 40, grifo nosso):

Prisão é de fato uma monstruosa opção. O cativeiro das cadeias perpetua-se ante a insensibilidade da maioria, como uma forma ancestral de castigo. Para recuperar, para ressocializar, como sonham os nossos antepassados? Positivamente, jamais se viu alguém sair de um cárcere melhor do que entrou. $\mathrm{E} \mathrm{o}$ estigma da prisão? Quem dá trabalho ao indivíduo que cumpriu pena por crime considerado grave? Os egressos do cárcere estão sujeitos a uma outra terrível condenação: o desemprego. Pior que tudo, são atirados a uma obrigatória marginalização. Legalmente, dentro dos padrões convencionais não podem viver ou sobreviver. A sociedade que os enclausurou, sob o pretexto hipócrita de reinseri-los depois em seu seio, repudia-os, repele-os, rejeita-os. Deixa, aí sim, de haver alternativa, só o ex-condenado tem uma solução: incorporar-se ao crime organizado. Não é demais martelar: a cadeia fabrica delinquentes, cuja quantidade cresce na medida e na proporção em que for maior o número de condenados. 
Logo, é importante que, ao determinar a privação da liberdade do indivíduo, se esteja ciente da seriedade de seus nefastos efeitos, até como forma de ponderação de sua necessidade no caso concreto.

\subsection{Qual caminho o magistrado poderá seguir?}

Evidenciada a ineficácia do atual sistema punitivo, em especial que a pena privativa de liberdade está longe de cumprir sua finalidade ressocializadora, prestando-se, muitas vezes, como instrumento de violação da dignidade da pessoa, resta examinar se tais questões podem e devem ser ponderadas pelo juiz ao prolatar a sentença condenatória e fixar a respectiva pena.

Ainda que não se possa atribuir ao Poder Judiciário a responsabilidade pela má gestão do sistema penitenciário e o desatendimento da declarada finalidade ressocializadora, não há mais espaço para a atuação meramente subsuntiva do juiz, aplicando os fatos à lei positiva, sem ponderar as implicações decorrentes das falhas do sistema punitivo penal.

Logo, em defesa dos direitos humanos fundamentais, parece decisiva uma atuação criativa do Poder Judiciário.

Nesse contexto, abre-se um parêntese para refletir entre o dilema celeridade e criatividade que o referido órgão necessita.

Sobre o tema, Rosa (2014, p. 114-115) pondera que a celeridade implica estabelecimentos de padrões cada vez mais uniformes, o que, de certa forma, soa incompatível com a construção de verdades, já que o excesso de velocidade inviabiliza a visão e a necessária compreensão do caso concreto. Ainda que se trate de atividade hercúlea, não se tendo notícias sobre a descoberta de uma solução para tal impasse, é inegável a necessidade de envidar esforços pessoais para que ambas caminhem juntas, em equilíbrio (MALGARIN, 2015, p. 44). 
Muitas têm sido as vozes no Judiciário em defesa da dignidade humana do cidadão preso, especialmente na execução penal, já que é nessa fase que deveriam ser atendidas as finalidades de prevenção especial positiva e negativa, a exemplo das decisões que deferem prisão domiciliar na hipótese de superlotação ou regime inadequado.

Já na fase de aplicação da pena, a adoção de medidas relacionadas à prevenção especial não são vislumbradas com a mesma frequência. Talvez assim o seja em razão de que é usual o entendimento de que, nessa fase (aplicação da pena), se deve atentar apenas para as funções de retribuição e prevenção geral positiva, cabendo exclusivamente à execução penal o atendimento da finalidade preventiva especial da pena.

Procura-se, entretanto, quando não for possível a substituição por pena restritiva de direitos, salientar a importância do julgador, valendo-se do contato direto com o réu e com as circunstâncias do caso, e atentar para as situações em que o encarceramento não se mostre necessário, tampouco eficaz no atendimento das finalidades de retribuição e prevenção, o que será abordado a seguir.

\subsection{Critérios para a fixação do regime inicial mais brando}

Seguindo a linha do raciocínio dogmático penal do sistema de garantias e não apenas como fixação normativa do poder punitivo, propõe-se a fixação de regime mais brando (aberto) nas hipóteses em que a pena cominada implica em regime mais rigoroso, a teor do $\S 2^{\circ}$ do art. 33 do Código Penal.

Inicialmente, cumpre salientar que, de acordo com o $\S 3^{\circ}$ do mesmo dispositivo, a determinação do regime inicial de cumprimento da pena será feita em observância aos critérios previstos no art. 59 do Código Penal. Da redação do disposi- 
tivo, doutrina e jurisprudência, conclue-se que as circunstâncias judiciais devem ser levadas em consideração no estabelecimento da pena necessária e suficiente para reprovação e prevenção do crime.

Esse, aliás, corresponde ao entendimento das Cortes Superiores no sentido de que a "fixação do regime inicial de cumprimento da pena não está condicionada somente ao quantum da reprimenda, mas também ao exame das circunstâncias judiciais do art. 59 do Código Penal, conforme remissão do art. 33, $\S 3^{\circ}$, do mesmo diploma legal." (BRASIL, 2013).

Tal entendimento é reiteradamente utilizado como justificativa para fixação de regime mais gravoso do que aquele previsto em lei, na hipótese de existência de circunstâncias judiciais desfavoráveis.

Nesse sentido, colacionam-se julgados:

RECURSO ORDINÁRIO EM HABEAS CORPUS. PENAL. CRIME DE TRÁFICO DE DROGAS. FIXAÇÃO DO REDUTOR PREVISTO NO ART. 33, $4^{\circ}$, DA LEI DE DROGAS. PATAMAR MÁXIMO. INAPLICABILIDADE. REGIME INICIAL DE CUMPRIMENTO DE PENA MAIS GRAVOSO. POSSIBILIDADE. RECURSO ORDINÁRIO AO QUAL SE NEGA PROVIMENTO. I - O entendimento do STF é pacífico no sentido de que o juiz não está obrigado a aplicar o máximo da redução prevista quando presentes os requisitos para a concessão desse benefício, possuindo plena discricionariedade para impor a redução no patamar que entenda necessário e suficiente para a reprovação e a prevenção do crime. II - Este Tribunal já sedimentou orientação pela possibilidade da imposição de regime mais gravoso do que o previsto para o quantum de pena aplicado, desde que tal decisão seja devidamente fundamentada. Essa orientação, inclusive, está estampada na Súmula 
719 do STF: “A imposição do regime de cumprimento mais severo do que a pena aplicada permitir exige motivação idônea. Tudo em conformidade com o que se deu, na espécie. III - Recurso ordinário ao qual se nega provimento. Prejudicado o exame do pedido de liminar. (BRASIL, 2014b).

"HABEAS CORPUS" - PACIENTE CONDENADO A PENA RECLUSIVA INFERIOR A 08 (OITO) ANOS ESTIPULAÇÃO DE CUMPRIMENTO DE PENA EM REGIME INICIAL FECHADO - POSSIBILIDADE - NECESSIDADE, CONTUDO, DE TAL FIXAÇÃO INICIAL RESULTAR DE DECISÃO ADEQUADAMENTE FUNDAMENTADA (SÚMULA 719/STF) PEDIDO DE INGRESSO EM REGIME INICIAL DE CUMPRIMENTO DE PENA MAIS BRANDO - CIRCUNSTÂNCIAS JUDICIAS INTEIRAMENTE DESFAVORÁVEIS AO RÉU - INVIABILIDADE DE O SUPREMO TRIBUNAL FEDERAL, EXAMINANDO PRESSUPOSTOS DE ÍNDOLE SUBJETIVA, DETERMINAR, NO ÂMBITO ESTREITO DO "HABEAS CORPUS", O IMEDIATO CUMPRIMENTO DA PENA DO SENTENCIADO EM REGIME MENOS GRAVOSO - RECURSO DE AGRAVO IMPROVIDO.

- O preceito inscrito no art. 33, § 2 , “b”, do Código Penal não obriga o magistrado sentenciante, mesmo tratando-se de réu sujeito a pena não superior a oito anos de prisão, a fixar, desde logo, o regime penal semiaberto. A norma legal em questão permite ao juiz impor ao sentenciado regime penal mais severo, desde que o faça, no entanto, em decisão suficientemente motivada (Súmula 719/STF). A opção pelo regime menos gravoso, desse modo, constitui mera faculdade legal reconhecida ao magistrado. Precedentes. (BRASIL, 2015)

PENAL. PROCESSUAL PENAL. APELAÇÃO CRIMINAL. CRIME CONTRA A SAÚDE PÚBLICA. TRÁFI- 
CO DE DROGAS (LEI 11.343/2006, ART. 33, CAPUT). SENTENÇA CONDENATÓRIA. RECURSO DA DEFESA. MÉRITO. MATERIALIDADE E AUTORIA NÃO IMPUGNADAS. DOSIMETRIA. CAUSA ESPECIAL DE DIMINUIÇÃO DA PENA ( $\S 4^{\circ}$ DO ART. 33 DA LEI DE DROGAS). CIRCUNSTÂNCIAS FÁTICAS QUE REVELAM DEDICAÇÃO AO TRÁFICO DE DROGAS. INCOMPATIBILIDADE COM O BENEFÍCIO. PEDIDO DE ABRANDAMENTO DO REGIME FECHADO. REPROVABILIDADE CONCRETA DA AÇÃO NÃO AFASTADA. OBSERVÂNCIA DO VERBETE 719 DA SÚMULA DE JURISPRUDÊNCIA DO STF. SENTENÇA MANTIDA.

- A existência de substrato probatório a revelar a prática reiterada do tráfico de drogas, reforçada pela apreensão de quantidade significativa do produto espúrio, a evidenciar a dedicação à atividade, obsta a concessão do benefício estampado no $\S 4$ do art. 33 da Lei 11.343/2006.

- É possível adotar regime inicial mais severo do que o alcançado pelo montante da pena quando presentes circunstâncias fáticas e judiciais desfavoráveis que demonstrem a maior periculosidade da conduta, de modo a não traduzir a fixação de regime mais brando medida suficiente para reprovação e prevenção do crime, nos termos do art. $33, \S 3^{\circ}$, cumulado com o art. 59 , ambos do Código Penal e do verbete 719 da súmula de jurisprudência do Supremo Tribunal Federal. - Recurso conhecido e desprovido. (SANTA CATARINA, 2020).

Tal fundamento explanado nos referidos julgados decorre do entendimento de que a pena deve ser suficiente para atender às finalidades de reprovar e prevenir o delito, pois esse é o critério estabelecido pelo art. 59 do Código Penal.

A aferição da suficiência do regime nas hipóteses de agravamento se dá com base na valoração negativa de circunstân- 
cias judiciais, as quais demonstrariam a insuficiência do regime positivo, diante das peculiaridades daquele caso concreto.

Observa-se que não é a simples existência de circunstâncias judiciais valoradas negativamente que autoriza o agravamento do regime, mas sim o juízo de necessidade e suficiência desse regime para atender às finalidades de reprovação e prevenção do delito (MALGARIN, 2015, p. 49).

Contudo, no sentido de que o juiz poderá deixar de lado o regime objetivamente fixado pela lei quando observar que regime menos gravoso é suficiente para atender às finalidades da pena, não é o entendimento firmado nas cortes superiores (BRASIL, 2012).

Verifica-se que o mesmo critério da necessidade e suficiência deveria ser utilizado tanto para agravar, quanto para abrandar o regime.

Nesse diapasão, colhe-se julgado recente do Tribunal de Justiça de Santa Catarina:

APELAÇÃO CRIMINAL. RÉUS SOLTOS. AMBOS CONDENADOS POR ROUBO MAJORADO PELO CONCURSO DE PESSOAS (ART. 157, $\S 2^{\circ}$, II, DO CP) E UM DELES CONDENADO POR FALSA IDENTIDADE (ART. 307 DO CP). RECURSOS DA DEFESA E DO MINISTÉRIO PÚBLICO. [...].

RECURSO DA ACUSAÇÃO: DOSIMETRIA. PEDIDO DE REFORMA DO REGIME INICIAL, DO ABERTO PARA O SEMIABERTO. RECURSO CONHECIDO E DESPROVIDO. I. REGIME INICIAL.

"O preceito inscrito no art. $33, \S 2^{\circ}$, "b", do Código Penal não obriga o magistrado sentenciante, mesmo tratando-se de réu sujeito a pena não superior a oito anos de prisão, a fixar, desde logo, o regime penal semiaberto" (STF, HC 125589 AgR, julgado em 19/05/2015).

$\mathrm{Na}$ hipótese, considerando que a escolha pelo regime mais brando que o correspondente à pena aplicada restou 
devida e adequadamente fundamentada pelo Magistrado a quo, não há razões para alteração do regime. (SANTA CATARINA, 2018).

Ainda do corpo do voto:

Recurso da Acusação: da alegada necessidade de fixação do regime inicial semiaberto.

Requer a Acusação tão somente a fixação do regime inicialsemiaberto para cumprimento da pena.

Sustenta, nesse sentido, que ambos os acusados foramcondenados a 5 anos e 4 meses de reclusão, patamar que, em atenção ao estabelecido no art. $33, \S 2^{\circ}$, b, do $\mathrm{CP}$, imporia a fixação do regime inicialsemiaberto (fls. 585/588).

O pedido não comporta acolhimento.

Isso porque, apesar da fixação de pena superior a 4 anos dereclusão refletir, via de regra e com base no art. $33, \S$ $2^{\circ}$, b, do CP, a aplicação do regime inicial semiaberto, não posso deixar de notar que a escolha do regimeinicial de cumprimento da pena é ato discricionário do Julgador. Assim, considerando que o Magistrado a quo apresentou fundamentação idônea para a fixação de regime mais brando que o correspondente à pena aplicada (no caso: circunstâncias judiciais favoráveis,primariedade do réu, situação deplorável do sistema carcerário e suficiência na repressão e prevenção do delito), não vislumbro motivos para alterá-lo.

Com efeito, consignou o Sentenciante Marcelo Carlin:

No que diz respeito ao regime de cumprimento das penas impostas, é de se observar cuidadosamente as circunstâncias pessoais dos acusados.

Neste tocante, imperioso ressaltar que as circunstâncias judiciais apuradas na primeira fase da dosimetria (art. $59, \mathrm{CP})$ revelaram-se como favoráveis aos acusados. Além disso,ambos os acusados são primários, não havendo qualquer questão prejudicial aos mesmos ou mes- 
mo qualquer notícia de que tenham se envolvido em novas práticas criminosas após suas solturas.

Portanto, é necessário considerar que militam em seu favor circunstâncias judiciais, atenuante e vidas sucessivas, o que por si só, já seria suficiente para levar este magistrado ao convencimento de que a fixação de regime de execução mais brando que o semiaberto se impõe. Não fosse só, é cediço que as condições atuais de execução de pena no regime semiaberto apresentam óbices inarredáveis à recuperação do apenado, além de na prática não serem respeitadas as regras inerentes à esta forma de execução criminal.Neste Estado de Santa Catarina, por exemplo, em regra, os apenados dormem na Penitenciária (quando não passam o dia por lá mesmo o que constitui um verdadeiro regime fechado para o cumprimento da pena).

Sobre as condições em que se desenvolve a população carcerária brasileira:http://www.cnj.jus.br/sistema-carcerario-e-execucao-penal/cidadania-nospresidios.

Ademais disso, segundo informações do próprio Conselho Nacional de Justiça:Ao mesmo tempo há um déficit de 354 mil vagas no sistema carcerário. Se se considerarem os mandados de prisão em aberto 373.991 a população carcerária saltaria para mais 1 milhão de pessoas. Ora, o sujeito, apesar de criminoso, já inseridos de volta à comunidade e ao mercado de trabalho, seria submetido ao cumprimento de um mandado de prisão e recolhimento em penitenciária para lá permanecer pelo pequeno espaço de tempo restante, o que certamente significaria grande retrocesso na sua recuperação em andamento. Estabelecer o regime aberto para o cumprimento da pena imposta aos acusados é providência, pois, imperativa, que se mostra mais apta a cumprir a finalidade da pena no caso concreto, sendo suficiente à repressão e prevenção de delitos. [...] Assim, considerando que a fundamentação trazida pelo Magistradosentenciante 
mostrou-se idônea, mantenho o regime inicial fixado na sentença. [...]. (SANTA CATARINA, 2018).

Logo, sendo favoráveis as circunstâncias judiciais, há que se aferir se o regime legalmente previsto é necessário e suficiente para atender aos fins da pena ou se o mesmo objetivo pode ser atingido com o menos gravoso.

Nesse sentido, Greco (2014, p. 119) mencionou que, para que a pena "seja justa, e não um ato de puro arbítrio, ou, no sentido contrário, de protecionismo, não poderá ir além ou aquém de sua necessidade, devendo, pois, ser aquela suficiente para a reprovação e a prevenção do crime".

Cumpre ressaltar exemplo que se encaixa à aplicação de regime mais brando, no qual o sentenciado tenha sido condenado à pena de 5 anos e 4 meses de reclusão por infração ao crime de roubo majorado pelo emprego de arma branca (art. 157, § $2^{\circ}$, VII, do CP).

Cumpre informar que todas as circunstâncias judiciais lhe são favoráveis, não havendo nenhuma agravante em seu desfavor. E que, além de não apresentar antecedentes, não existam inquéritos policiais em aberto ou quaisquer outros registros policiais. Suponha-se, ainda, que a instrução demonstre que se tratava de usuário de drogas e que o roubo foi cometido para seu consumo, bem como que não se tenha notícias de práticas delitivas posteriores, levando a crer que se tratou de fato isolado. Além disso, imagine-se que venha aos autos informação de que o réu está em tratamento da dependência química, encontra-se trabalhando, constituiu família ou, de alguma forma, demonstra estar reintegrado à comunidade da qual participa.

Assim, ainda que a pena seja determinada em seu mínimo (5 anos e 4 meses), automaticamente seria fixado o regime semiaberto, pois esse é o padrão e essa parece ser a única res- 
posta legal para o crime de roubo majorado pelo emprego de arma branca.

Com o caso demonstrado, procura-se salientar que o regime legal, na maioria dos casos, é automaticamente fixado. Dificilmente são feitas maiores ponderações se efetivamente o regime legal mostra-se necessário e suficiente para atender à reprovação e prevenção no caso concreto, ou se essas finalidades poderiam ser satisfeitas por meio de regime mais brando. E, quando são feitas ponderações, objetivam o agravamento do regime.

Portanto, se o regime legal não é adequado aos fins da pena, já que, no caso concreto, tem a potencialidade de não apenas interromper a reinserção na comunidade que já vem ocorrendo, mas também de aprimorar práticas delitivas, não há como sustentar sua aplicabilidade no caso concreto, sem mácula à proporcionalidade e à própria dignidade humana.

Isso porque, no Brasil, a maioria dos detentos em regime semiberto acaba, na prática, cumprindo a pena em regime fechado, em razão das péssimas condições do regime carcerário brasileiro.

No ano de 2014, apenas em 11 capitais brasileiras, os apenados ficavam reclusos exclusivamente em colônias agrícolas, industriais ou similares, conforme os ditames do Código Penal e da Lei de Execuções Penais (REGIME..., 2014).

Nessas circunstâncias, a fixação de regime mais brando não se trata de opção discricionária, mas sim de um imperativo, com fulcro na orientação de que a determinação do regime será feita em obediência aos critérios do art. 59 do Código Penal.

Trata-se, na verdade, de conferir efetiva aplicabilidade ao $\S 3^{\circ}$ do art. 33 do Código Penal como forma de conjugar a necessidade e a suficiência às duas funções atribuídas à pena. 
Não se prega que o regime aberto seja utilizado como regra, afastando as diretrizes estabelecidas no art. $33, \S 2^{\circ}$, do Código Penal. Ao contrário, inegável que a determinação do regime mais brando dependa de decisão fundamentada e deva encontrar substrato em elementos concretos constantes dos autos, os quais evidenciem que a fixação do regime legal pode representar a obtenção da finalidade inversa que espera da pena, interrompendo o processo, já em andamento, de reinserção na sociedade.

Trata-se, portanto, de atuação tendente a atenuar o rigor repressivo por meio da fixação de regime de cumprimento mais brando do que o legal, desde que presentes circunstâncias judiciais favoráveis, fazendo-se necessária a ponderação dos seguintes requisitos:

$$
\begin{aligned}
& \text { violação da dignidade no atual sistema carcerário; b) } \\
& \text { malefícios de potencial dessocialização; c) efetivo risco } \\
& \text { que a não segregação representa à sociedade; e d) atual } \\
& \text { condição de integração com a sociedade. (MALGARIN, } \\
& \text { 2015, p. 53). }
\end{aligned}
$$

Dessa forma, ante a ampliação da interpretação do regime de pena, busca-se se utilizar dogmática penal como sistema de garantias do indivíduo, sem afastar ou desmerecer o poder punitivo estatal.

\section{CONCLUSÃO}

A vinculação da pena privativa de liberdade ao fim retributivo e preventivo geral e especial, longe de representar sucesso no controle social, apenas reforçou esse modelo de pena, que se encontra em crise desde sua concepção. A frustração de suas distintas perspectivas conduz à conclusão de que a única missão que parece ser atendida é a mesma que a justificou em suas origens, qual seja, a meramente retributiva. 
A despeito dessas constatações, não se defendeu, no presente estudo, a abolição da pena privativa de liberdade. Longe disso, concluiu-se que seria necessária sua reformulação e aperfeiçoamento, limitando-se essa aos casos estritamente necessários.

Não se pode negar o inadimplemento da Administração Pública no tocante à realidade do sistema penal brasileiro, entretanto tal circunstância não se presta a justificar a omissão do Poder Judiciário. Assim, procurou-se chamar a atenção para o fato de que o operador do direito, efetivamente comprometido com a Constituição, deve atuar de forma incisiva e criativa, utilizando-se dos mecanismos à sua disposição na atual sistemática penal, a fim de atenuar o rigor repressivo quando tal medida não encontrar justificativa diante do caso concreto.

O presente estudo teve como objetivo chamar a atenção para a possibilidade de ampliação da utilização de um desses mecanismos, consistente na possibilidade legal de fixação do regime aberto, mesmo quando o regime legal seja mais gravoso.

Por meio do raciocínio da proibição do excesso, no intuito de evitar a punição desnecessária ou desproporcional de comportamento penalmente relevante, o legislador estabelece que o julgador, após a individualização da pena, utilize os critérios previstos no art. 59 do Código Penal para a fixação do regime inicial.

A leitura desse dispositivo legal permite concluir que não são as circunstâncias judiciais individualmente consideradas que ditam o regime, mas sim que o juiz, atentando para essas circunstâncias, estabelecerá o regime conforme juízo de necessidade e suficiência para atender aos fins de reprovação e prevenção.

A problemática, ao que parece, refere-se ao fato de que o regime é usualmente fixado de forma padronizada, em obediência ao quantum estabelecido em lei, sem ponderar se esse 
se mostra necessário e suficiente para atender à reprovação e à prevenção no caso concreto, ou se esses fins podem ser igualmente atingidos por meio de regime mais brando.

Tal exame, entretanto, é imprescindível dentro da concepção de que a dogmática penal deve ser aplicada como sistema de garantias do indivíduo. Assim, se o regime legal não é adequado aos fins da pena, já que, no caso concreto, tem a potencialidade de não apenas interromper a reinserção na comunidade que já vem ocorrendo, mas também de aprimorar práticas delitivas, não há como sustentar sua aplicabilidade no caso concreto, sem mácula à proporcionalidade e à própria dignidade humana.

Concluiu-se, portanto, que a fixação do regime aberto representa mecanismo eficiente para, de um lado, atender às finalidades da pena e, de outro, impedir a vulneração da dignidade do apenado, ao mesmo tempo em que atua de forma produtiva no processo de ressocialização já em curso, impedindo a dessocialização decorrente do encarceramento.

\section{REFERÊNCIAS}

BECCARIA, Cesare. Dos delitos e das penas. São Paulo: Martin Claret, 2006.

BITENCOURT, Cezar Roberto. Falência da pena de prisão: causas e alternativas. 4. ed. São Paulo: Saraiva, 2012.

BRASIL. Decreto-lei No 2.848, de 7 de dezembro de 1940. Código Penal. Brasília, DF: Presidência da República, 1940. Disponível em: http://www.planalto.gov.br/ccivil_03/decreto-lei/del2848compilado. htm. Acesso em: 16 ago. 2020.

BRASIL. Superior Tribunal Federal. Habeas Corpus 121729 SP. Relator: Min. Gilmar Mendes, 2 de abril 2014a. Disponível em: https://stf.jusbrasil.com.br/jurisprudencia/25038229/medida-cautelar-no-habeas-corpus-hc-121729-sp-stf?ref=serp. Acesso em: 16 ago. 2020. 
BRASIL. Superior Tribunal Federal (2. Turma). Ag. Reg. no habeas corpus 125.589 Ceará. Relator: Min. Celso de Melo, 19 de Maio de 2015. Disponível em: https://stf.jusbrasil.com.br/jurisprudencia/863965391/agreg-no-habeas-corpus-agr-hc-125589-ce-ceara-0000231-5020141000000/inteiro-teor-863965401?ref=serp. Acesso em: 16 ago. 2020.

BRASIL. Superior Tribunal Federal. Habeas Corpus 116462 DF. Relatora: Min. Rosa Weber, 21 de maio de 2013. Disponível em: https://stf.jusbrasil.com.br/jurisprudencia/23345900/habeas-corpus-hc-116462-df-stf/inteiro-teor-111687317?ref=serp. Acesso em: 16 ago. 2020.

BRASIL. Superior Tribunal Federal. Habeas corpus n. 109.821/MT. Relator: Min. Dias Toffoli, 8 de maio 2012. Disponível em: https://stf. jusbrasil.com.br/jurisprudencia/21840114/habeas-corpus-hc-109821-mt-stf/inteiro-teor-110463666?ref=serp. Acesso em: 16 ago. 2020.

BRASIL. Supremo Tribunal Federal (2. Turma). Recurso oridinário em Habeas Corpus RHC 12260 ES. Relator: Min. Ricardo Lewandowski, 25 de Junho de 2014b. Disponível em: https://stf.jusbrasil.com.br/jurisprudencia/25232476/recurso-ordinario-em-habeas-corpus-rhc-122620-es-stf/ inteiro-teor-133959904?ref=serp. Acesso em: 16 ago. 2020.

GRECO, Rogério. Curso de direito penal. 17 ed. Rio de Janeiro: Impetus, 2015.

GRECO, Rogério. Direito penal do equilíbrio: uma visão minimalista do Direito Penal. 7. ed. Niterói: Impetus, 2014.

MALGARIN, Luciana. Fixação do regime inicial de cumprimento da pena mais brando: alternativa à padronização da punição. 2015. 56 f. Monografia (Especialização em Direito e Gestão Judiciária) - Centro de Estudos Jurídicos do Poder Judiciário de Santa Catarina, Florianópolis, 2015.

MASSON, Cleber Rogerio. Direito penal esquematizado. Parte geral. 3. ed. rev., atual. e ampl. Rio de Janeiro: Forense, 2009.

REGIME semiaberto praticamente não existe no Brasil. Migalhas, 29 jan. 2014. Disponível em: https:/www.migalhas.com.br/quentes/194415/regime-semiaberto-praticamente-nao-existe-no-brasil. Acesso em: 16 ago. 2020. 
ROSA, Alexandre Morais da; AMARAL, Augusto Jobim do. Cultura da punição: a ostentação do horror. Rio de Janeiro: Lumen Juris, 2014. ROXIN, Claus. Derecho penal: parte general: fundamentos de la estrutura de la teoria del delito. Madrid: Editorial Civistas, 1997. v. 1.

SANTA CATARINA. Apelação Criminal n. 002731741.2012.8.24.0023, da Capital. Relator: Des. Júlio César M. Ferreira de Melo, 16 de outubro de 2018).Disponível em: https://tj-sc. jusbrasil.com.br/jurisprudencia/639312512/apelacao-criminal-apr-273174120128240023-capital-0027317-4120128240023/inteiro-teor-639312580?ref=serp. Acesso em: 16 ago. 2020.

SANTA CATARINA. Tribunal de Justiça. Apelação Criminal n. 0003365-25.2019.8.24.0011, de Brusque. Relator: Des. Carlos Alberto Civinski, 13 de fevereiro de 2020. Disponível em: https://www.jusbrasil.com.br/diarios/285010506/djsc-jurisdicional-21-02-2020-pg-285. Acesso em: 16 ago. 2020.

SANTOS, Juarez Cirino dos Santos. Direito penal: parte geral. 3. ed. Curitiba: 2008.

SILVA, Evandro Lins e. De Beccaria a Filippo Gramatica. In: FRAGOSO ADVOGADOS, Rio de Janeiro, 2017. Disponível em: http://www. fragoso.com.br/wp-content/uploads/2017/10/20171002212053-beccaria_filippo_gramatica_4.pdf. Acesso em: 20 jul. 2020.

VIEIRA, Adriana Nunes. Surgimento da proibição de se infligir uma pena cruel: o mito da humanização da pena. Centro di ricerca interuniversitario su carcere, ADIR: l'altro diritto, Pisa, 2007. Disponível em: http:// www.adir.unifi.it/rivista/2007/dias/cap1.htm. Acesso em: 18 ago. 2020.

ZAFFARONI, Eugenio Raúl.Manual de direito penal brasileiro. 9. ed. rev. e atual. São Paulo: Revista dos Tribunais, 2013. v. 1.

Recebido em: 01/06/2020

Aprovado em: 03/08/2020 